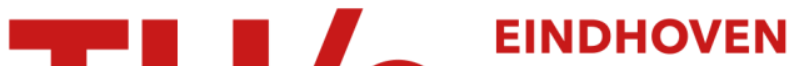 UNIVERSITY OF TECHNOLOGY
}

\section{The influence of surface functionality on the activity of carbon- supported catalysts}

\section{Citation for published version (APA):}

Derbyshire, F. J., Beer, de, V.H. J., Abotsi, G. M. K., Scaroni, A. W., Solar, J. M., \& Skrovanek, D. J. (1986).

The influence of surface functionality on the activity of carbon-supported catalysts. Applied Catalysis, 27(1), 117-

131. https://doi.org/10.1016/S0166-9834\%2800\%2981051-9, https://doi.org/10.1016/S0166-9834(00)81051-9

\section{DOI:}

10.1016/S0166-9834\%2800\%2981051-9

$10.1016 / S 0166-9834(00) 81051-9$

Document status and date:

Published: 01/01/1986

\section{Document Version:}

Publisher's PDF, also known as Version of Record (includes final page, issue and volume numbers)

\section{Please check the document version of this publication:}

- A submitted manuscript is the version of the article upon submission and before peer-review. There can be important differences between the submitted version and the official published version of record. People interested in the research are advised to contact the author for the final version of the publication, or visit the $\mathrm{DOI}$ to the publisher's website.

- The final author version and the galley proof are versions of the publication after peer review.

- The final published version features the final layout of the paper including the volume, issue and page numbers.

Link to publication

\section{General rights}

Copyright and moral rights for the publications made accessible in the public portal are retained by the authors and/or other copyright owners and it is a condition of accessing publications that users recognise and abide by the legal requirements associated with these rights.

- Users may download and print one copy of any publication from the public portal for the purpose of private study or research.

- You may not further distribute the material or use it for any profit-making activity or commercial gain

- You may freely distribute the URL identifying the publication in the public portal.

If the publication is distributed under the terms of Article 25fa of the Dutch Copyright Act, indicated by the "Taverne" license above, please follow below link for the End User Agreement:

www.tue.nl/taverne

Take down policy

If you believe that this document breaches copyright please contact us at:

openaccess@tue.nl

providing details and we will investigate your claim. 
F.J. DERBYSHIRE, V.H.J. de BEER a , G.M.K. ABOTSI, A.W. SCARONI, J.M. SOLAR and

D.J. SKROVANEK

Department of Materials Science and Engineering, Fuel Science Program, The Pennsylvania State University, University Park, PA 16802, USA.

¿Laboratory for Inorganic Chemistry and Catalysis, Eindhoven University of Technology, P.0. Box 513,5600 MB Eindhoven, The Netheriands.

(Received 27 rebruary 1986, accepted 29 Apri1 1986)

\section{ABSTRACT}

The aim of this research is to investigate how the presence of surface functional groups can influence the activity of carbon-supported MoS 2 catalysts for coal asphaltene hydrogenation. Porous carbons were subjected to various chemical treatments in order to introduce oxygen and nitrogen surface functionalities prior to impregnation with ammonium tetrathiomolybdate. Supports and catalysts were examined by FTIR. Preoxidation of polymer-derived carbons lowered catalyst activity whereas preoxidation of a carbon black composite support increased it. Similar mixed results have been reported in the 1 iterature. The modified catalytic activity cannot be unequivocally attributed to surface oxygen. Qualitatively, it is considered that these groups exert some influence, but it is the structure of the carbon which is ultimately the controlling factor. In some cases, oxidation may introduce sites which promote interaction with metal species and, in others, oxidation may modify or destroy favourable sites which are already extant.

Prenitriding was found to have a distinct influence in enhancing catalyst activity. The presence of nitrogen-containing surface groups may provide preferential sites for the adsorption of Mo species.

\section{INTRODUCTION}

In previously reported research [1], the hydrodesulfurization (HDS) activities and the propensities for carbon deposition were determined for a series of catalysts prepared on carbon and alumina supports. The results showed that the HDS activities were higher and the coking propensities were lower on the carbon than on the alumina supported catalysts and that, for the former, the activity was strongly dependent upon the nature of the carbon.

It is obvious ly of interest to identify those characteristics of carbon supports which are influential in determining catalyst properties. However, the carbons used in the earlier research were of different origin and varied in their chemical structure, textural properties and content of impurities. Further interpretation of the results was thus precluded in the absence of a sound basis for the comparison of data.

In the light of present knowledge, it seems that, ceteris paribus, catalyst 
activity is strongly influenced by the interaction between the carbon surface and the deposited metal species. This interaction can be instrumental in controlling the dispersion of the activc species and valence state of the metal.

For a given precursor compound, a review of the literature suggests that catalyst activity is related to active sites on the carbon surface or to the presence of surface functional groups.

Ehrburger and co-workers [2] observed that the dispersion of platinum on carbon black particles increased with the extent of gasification of the support. They proposed that the effect of gasification was to increase the heterogeneity of the carbon surface which raised the potential energy barrier for platinum diffusion. The surface oxygen functionality did not appear to influence metal dispersion: similar dispersions were measured for platinum loaded on a sample of carbon which had been burned-off to $21.4 \%$ and for a sample of the same material which was first reduced in hydrogen at $950^{\circ} \mathrm{C}$ to remove oxygen complexes before platinum addition. The catalytic activities of these materials were not determined. These results suggest that it is principally carbon active sites which influence metal dispersion. That is, sites which "exist on the carbon surface where the valency is not satisfied. In a "clean" carbon surface, these sites would be located on the edges of the exposed layer planes as well as at points of imperfections in the structure including vacancies, dislocations, and steps on the outer basal plane" [3].

other results suggest that the type and concentration of surface functional groups can modify catalyst activity. It has been shown that the catalytic activity of unloaded carbons, for reactions such as $\mathrm{SO}_{2}$ oxidation, can be greatly enhanced by treatment with $\mathrm{NH}_{3}$ or $\mathrm{HCN}$ at elevated temperatures. The change in activity is attributed to the incorporation of nitrogen into the carbon surface [4]. No results have yet been reported for the catalytic behavior of metals supported on such carbons.

Ryan and Stacey [5] found that active carbons were selective catalysts for the reaction of phosgene and formaldehyde to produce dichloromethane. They attributed the catalytic activity to the presence of polar acid or base sites on the carbon surfaces.

Other work has shown that the treatment of active carbons with phosphoric acid induces catalytic activity for the conversion of methanol to $C_{1}-C_{4}$ paraffins and olefins [6].

Vissers et a1. [7] applied a number of oxidative treatments to carbon supports, prior to loading with Mo or Co precursors, in an attempt to alter the dispersion of the active species. A11 of the treatments resulted in an increased concentration of oxygen-containing functional groups on the carbon surface. The effects on the activities of the catalysts for thiophene HDS were mixed; preoxidation enhanced activity in some cases and suppressed it in others. 
The available evidence indicates that the nature of the carbon surface and the presence of functional groups can have an important influence upon the properties of carbon-supported metal catalysts.

In this paper we present the results of a program of research which was intended to investigate the importance of surface functional groups on the activity of carbon-supported $\mathrm{MoS}_{2}$ catalysts. For this purpose, a single metal salt precursor and a single parent carbon were selected. Samples of the carbon were subjected to a number of chemical treatments in order to introduce different oxygen and nitrogen-containing functional groups.

\section{EXPERIMENTAL}

\section{Carbon supports}

The carbon used in this study, Ambersorb XE-340 (supplied by courtesy of Rohm and Haas Co.) is produced by the carbonization of a sulfonated styrene/diveny?benzene copolymer, and can be made in high purity with reproducible chemical and physical properties. It has a pore size distribution suitable for the hydrogenation of high-boiling liquids since a high proportion (ca. $70 \%$, by the method of Metcalfe et a7. [8]) of the pore volume is contained in mesopores (2-50 nm diameter). Surface area measurements by BET using $N_{2}$ as the adsorbate gas gave values of $399 \mathrm{~m}^{2} \mathrm{~g}^{-1}$, which is in good agreement with the manufacturer's data. Using $\mathrm{CO}_{2}$ as the adsorbate, the surface area was determined to be $635 \mathrm{~m}^{2} \mathrm{~g}^{-1}$. A comparison of the two surface areas suggests that the carbon contains an appreciab]e micropore volume $(0.8-2.0 \mathrm{~nm}$ diameter) [9]. The carbon particles are spherical in form (0.3 - $0.8 \mathrm{~mm}$ diameter) and hard and durable, with a crush strength greater than $3 \mathrm{~kg} /$ particle.

A few additional experiments were carried out using a carbon black composite support which was fabricated by the carbonization of a mixture of graphitized carbon black filler and polyfurfuryl alcohol binder. The carbon black particles were first graphitized by heat treatment to $2500^{\circ} \mathrm{C}$ for $2 \mathrm{~h}$ in flowing argon. The carbon black/binder mixture was subsequently carbonized by heating to $1200^{\circ} \mathrm{C}$ for $2 \mathrm{~h}$ in an atmosphere of flowing nitrogen. The preparation of carbon black composites has been described by schmitt et al. [10].

\section{Support treatment}

Samples of Ambersorb XF-340 were subjected to a number of different treatments intended to introduce oxygen or nitrogen functionalities to the carbon surface. Following each treatment, the carbons were repeatedly washed with distilled, deionized water. The treatments and their effects on the elemental composition and surface areas of the carbons are presented in Table 1.

A17 of the oxidative treatments increased the oxygen content of the carbons. The $\mathrm{HNO}_{3}$ and boiling concentrated $\mathrm{H}_{2} \mathrm{SO}_{4}$ treatments introduced the highest amounts of oxygen. The acid treatments also increased the nitrogen or the sulfur contents of the supports. 


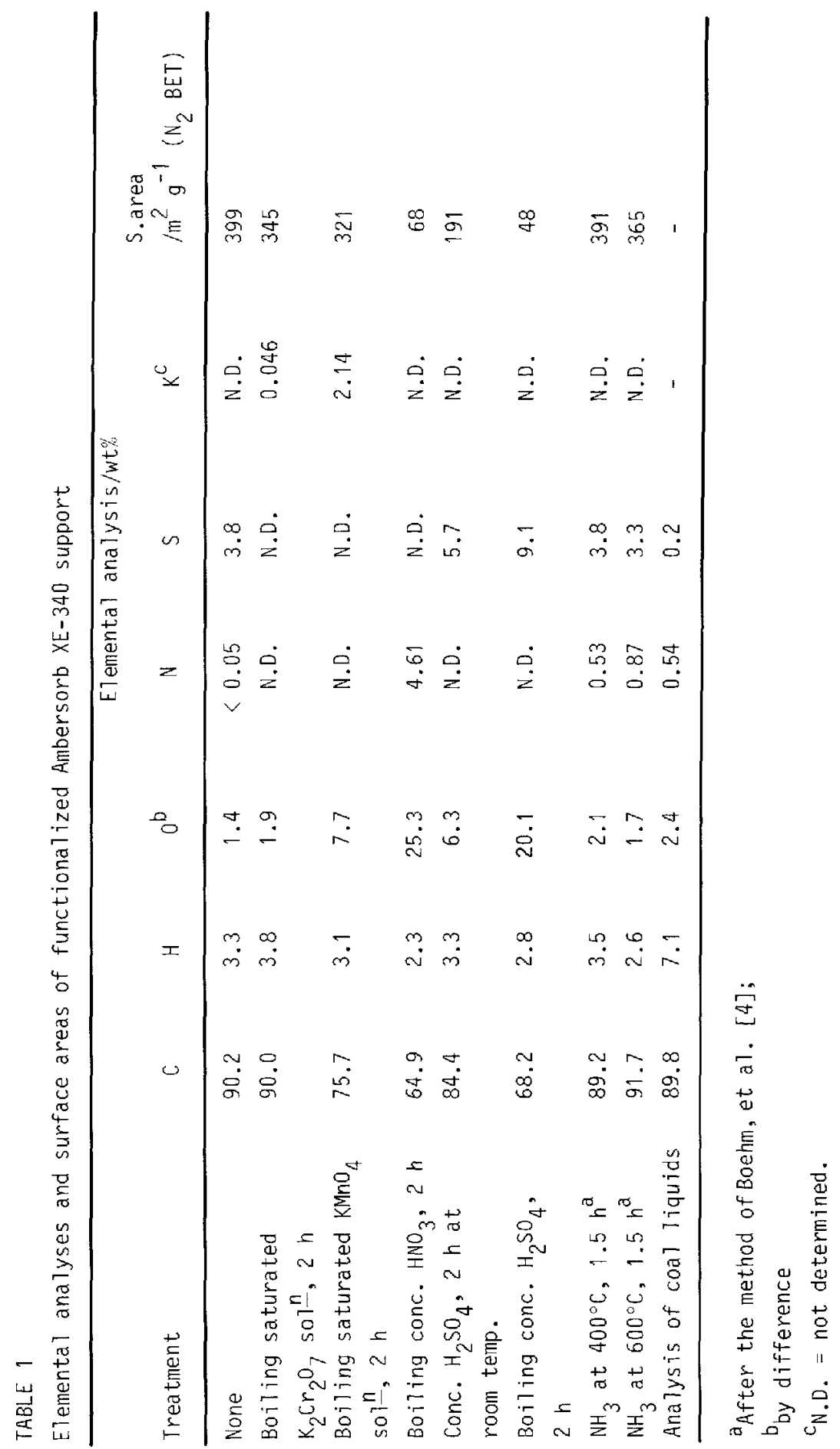


The treatments with potassium permanganate and potassium dichromate served principally to oxidize the carbon, the former reagent being the stronger oxidant of the two. In both cases, despite extensive post-treatment washing with distilled, deionized water, residual potassium was left on the carbon, as indicated by elemental analysis. Examination by $x$-ray diffraction confirmed that some potassium was present as potassium permanganate on the $\mathrm{KMnO}_{4}$-treated carbon.

These chemical treatments were intended to introduce oxygen functionalities while producing only minimum change to the textural properties. (oxidation through partial gasification can result in substantial carbon loss and can cause alterations to surface area and pore size distribution). As can be seen from Table 1, this aim was unsuccessful for those treatments with nitric and sulfuric acids which effected drastic reductions in surface area. Evidently, the attack by these acids was too severe and must have resulted in a collapse of the pore structure. Surprisingly, however, the structural integrity of the carbon particles was maintained.

The general procedure for introducing nitrogen functionality was adopted from Boehm et al. [4]. Reaction with ammonia at both 400 and $600^{\circ} \mathrm{C}$ increased the nitrogen content of the carbon but otherwise had little effect upon the elemental composition. There was some weight 7 oss by gasification during these reactions $\left(1 \%\right.$ at $400^{\circ} \mathrm{C}$ and $4.3 \%$ at $600^{\circ} \mathrm{C}$ ) with corresponding reductions in surface area.

\section{Catalyst preparation and characterization}

The carbons were impregnated with $3 \%$ wt Mo from solution using the incipient wetness technique. A solution of ammonium heptamolybdate was prepared by dissolution of the salt in a mixture of $90 \% \mathrm{H}_{2} \mathrm{O} / 10 \% \mathrm{EtOH}$. The presence of alcohol was found necessary to assist in wetting the carbon surface which is somewhat hydrophobic. The solution was then saturated with $\mathrm{H}_{2} \mathrm{~S}$ at room temperature to form the tetrathioammonium sa]t, $\left(\mathrm{NH}_{4}\right)_{2} \mathrm{MoS}_{2}$ [11]. Thus, the active catalyst form can be produced in situ, thereby eliminating the need for catalyst presulphiding. To achieve the required loading, repeated impregnations were required with the preparation being dried in vacuum at $100^{\circ} \mathrm{C}$ between each step. All of the prepared catalysts were used without further heat treatment.

The modified carbons, before and after loading, were analyzed by Fourier Transform Infrared Spectroscopy (FTIR) in diffuse reflectance (Digilab, Model FTS15E). The samples were prepared by first grinding to Tess than $0.3 \mathrm{~mm}$ dia. A solid mixture of $5 \%$ wt of the sample with $\mathrm{KBr}$ was intimately mixed by grinding in a mortar and pestle and the resulting mixture was placed in a Barnes diffuse reflectance unit. 


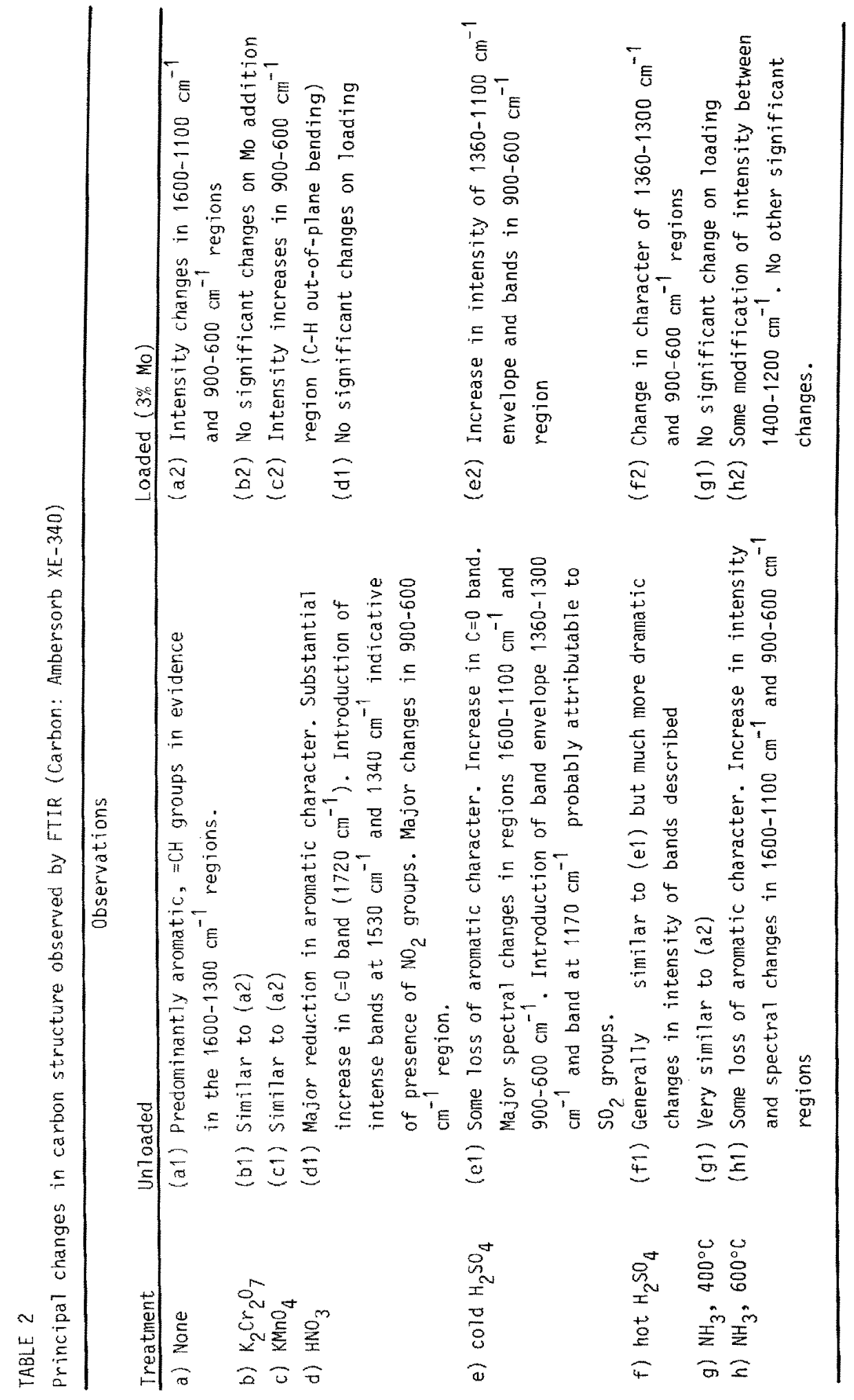


Catajyst actiyity

The prepared cataiysts were examined for their relative activities in the hydrogenative upgrading of coal liquids. The feed was a $454{ }^{\circ} \mathrm{C}$ recycle solvent Fraction from a cos: ijouetaction pijot piant (Lumus integrated Two-stage liquefaction unit processing subbituminous coa 7 ) and contained $38.2 \%$ asphaltenes (hexane-insolubie). The elemental analysis of this material is shown at the foot

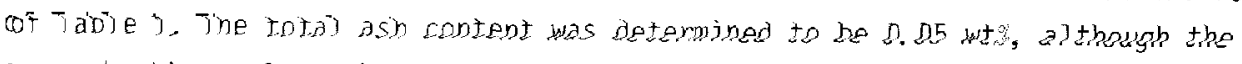
concentrations of specticic metais nave not seen determined.

Reactions were carried out in a batch tubing bombs of about 25 cc capacity. The following conditions were used; $5.0 \mathrm{~g}$ feed, $0.5 \mathrm{~g}$ catalyst, $7 \mathrm{MPa} \mathrm{H}_{2}$ (cold). Aporoximately $0.02 g$ of carbon disulfide were added to the reartion mixture to maintain the catalyst in sulfided form. The sealed reactor was immersed in a

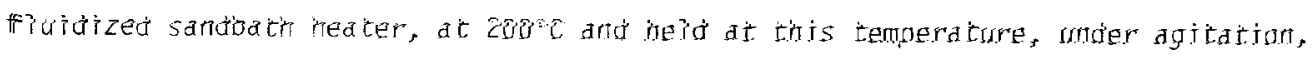

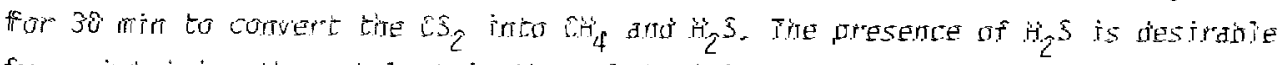
for me-irtarimirg the cataiyst in the suit-ided form. The temperatupe was then ratised

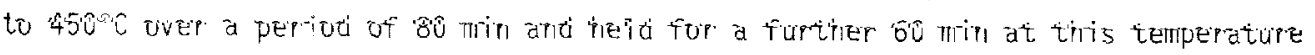
before removing the reactor and quenching in cold water.

The gases were vented from the bomb and were analyzed by gas chromatography.

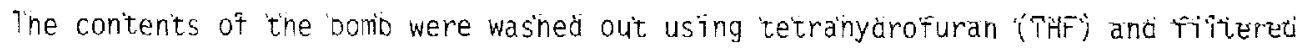
to recover the remaining solids. The THF was removed from the filtrate by vacuum evaporation and the material was then refluxed in hexane for $24 \mathrm{~h}$ to obtain a partition into hexane-soluble (oils) and hexane-insoluble (asphaltene) fractions.

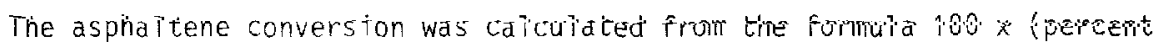
asphätenes in feed - percent asphalteses in product) ( (percent asphaltenes in feed).

\section{RESULTS AND DISCUSSION}

FTIR analysis of supports and catalysts

The main features observed in the FTIR spectra of the carbons and of the prepared catalysts are summarized in Table 2. After impregnation of the untreated carbon there was evident modification of the absorption bands at 812, 1160, 1240 , 1320,1420 and $1440 \mathrm{~cm}^{-1}$, Figure 1. Those at 810,1160 and $1240 \mathrm{~cm}^{-1}$ may correspond to $\mathrm{CH}$ substituents in the para position on a benzene ring. Similarly, the bands at $1320 \mathrm{~cm}^{-1}$ and $1420 \mathrm{~cm}^{-1}$ may represent $=\mathrm{CH}$, and $=\mathrm{CH}_{2}$, respectively. It may be implied that the impregnated metal salt or its decomposition products become chemically associated with aromatic ring substituents or to conjugated double bonds on the carbon surface.

After treatment with both $\mathrm{K}_{2} \mathrm{Cr}_{2} \mathrm{O}_{7}$, and $\mathrm{KMnO}_{4}$, the carbon FTIR spectra were both similar to that of the loaded parent carbon. Upon loading these oxidized carbons, there was no apparent change in the spectrum of the carbon reacted with potassium dichromate, and only minor changes for that treated with potassium permanganate. There was therefore 1ittle, if any, evidence from the FTIR spectra of any significant interaction between the carbon and the Mo surface species on these oxidized supports. 


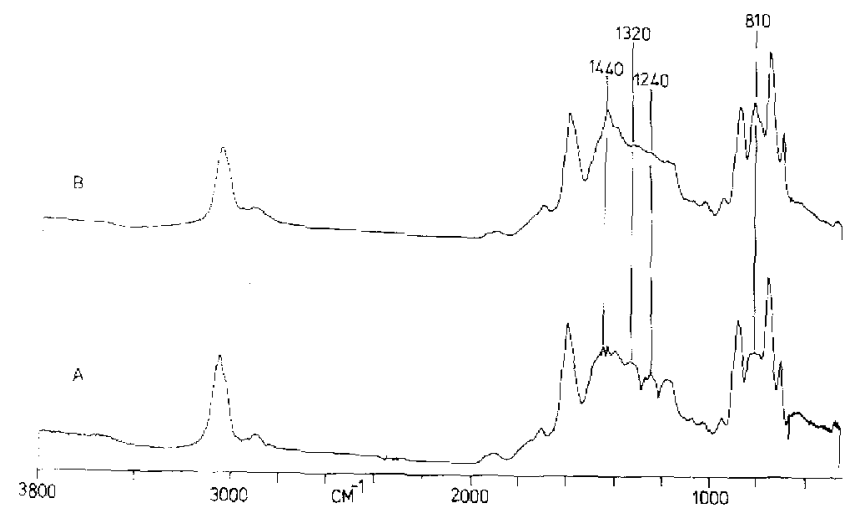

FIGURE 1 FTIR spectra of Ambersorb XE-340 (A) unloaded; (B) 7oaded with $3 \%$ Mo as ammonium tetrathiomolybdate.

As would be anticipated, the $\mathrm{HNO}_{3}$ and $\mathrm{H}_{2} \mathrm{SO}_{4}$ treatments caused more pronounced changes to the carbon structure. Notably there was a loss of aromaticity, as evidenced by a roduction in the intensity of the absorption band at $3070 \mathrm{~cm}^{-1}$ (aromatic $\mathrm{C}-\mathrm{H}$ stretch), and an increase in the intensity of the $\mathrm{C}=0$ band, at $1720 \mathrm{~cm}^{-1}$. Further, the $\mathrm{HNO}_{3}$ treatment introduced $\mathrm{NO}_{2}$ groups while both the cold and hot $\mathrm{H}_{2} \mathrm{SO}_{4}$ introduced $\mathrm{SO}_{2}$ groups to the carbon surface. The hot $\mathrm{H}_{2} \mathrm{SO}_{4}$ also produced absorption bands which may be due to $S=0$. The extensive structural changes in the Ambersorb carbon, which were brought about by these acid treatments and which are evident from the FTIR spectra, are consistent with the drastic losses in surface area discussed above. Following loading, there was little change in the spectrum of the $\mathrm{HNO}_{3}$ treated carbon in contrast to those treated with $\mathrm{H}_{2} \mathrm{SO}_{4}$ in which distinct spectral changes were observed upon impregnation, consistent with there being some interaction between the carbon surface and the impregnated metal species.

The spectrum of the carbon treated in ammonia at $400^{\circ} \mathrm{C}$ was similar to those obtained after oxidation by the potassium salts. After treatment with $\mathrm{NH}_{3}$ at $600^{\circ} \mathrm{C}$, there were more distinct alterations to the carbon structure as evidenced by a Toss of aromaticity and marked changes in the 600-900 and 1100-1600 $\mathrm{cm}^{-1}$ regions. The intensities of the bands in these regions increased after loading. In previous work by Boehm et a]. [4], it was suggested that the reaction of carbons with $\mathrm{NH}_{3}$ or HCN at elevated temperatures can lead to the incorporation of nitrogen into the aromatic layers as a pyridine-like species. The lone pairs of electrons of such hetero-atomic nitrogen species could be favorable sites for the interaction of Mo species with the support. If such species were produced in these experiments they would not be easily observed by FTIR because of the low nitrogen concentration and the coupling of $\mathrm{C}=\mathrm{N}$ vibrations with $\mathrm{C}=\mathrm{C}$ aromatic vibrations.

To pursue this aspect further, a sample of poly-4-vinylpyridine (containing 


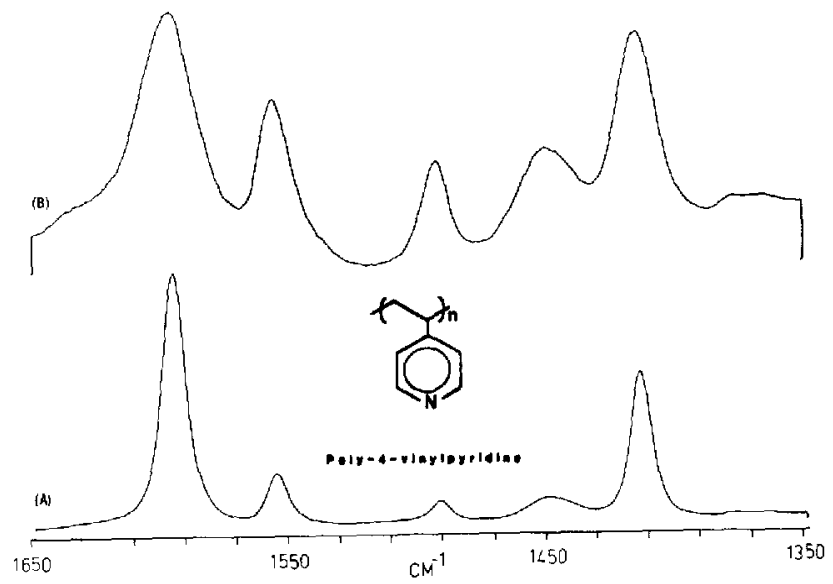

FIGURE 2 FTIR spectra of untreated poly-4-vinylpyridine (A) and after impregnation with $3 \%$ Mo as ammonium tetrathiomolybdate (B).

$12.3 \% \mathrm{~N}$ ) was loaded with $3 \%$ Mo and examined by FTIR. As shown in Figure 2, upon impregnation there was extensive broadening of the absorption bands which represent the vibrations of the $\mathrm{C}=\mathrm{N}$ and $\mathrm{C}=\mathrm{C}$ bonds in the pyridine ring. There was, in addition, a shift in the absorption frequency to lower wave numbers. Both of these features are indicative of there being a strong chemical interaction between Mo species and delocalized electrons (due to $\mathrm{C}=\mathrm{C}$ and $\mathrm{C}=\mathrm{N}$ bands) and/or the lone pairs of electrons on the nitrogen atoms in the polymer.

The implication from the foregoing is that, if similar nitrogen functionalities were present on the carbon, they could provide preferred sites for the adsorption of Mo species. The specific nature of the nitrogen-containing functionalities is not, however, known. Furthermore, the type and concentration of nitrogen (or other) groups which can be introduced by chemical reaction will evidently be dependent upon the carbon structure and will be affected by factors such as the degree of structural order, crystallite size, the concentration of dislocations and vacancies and the proportion of edge to basal planes which are exposed at the surface. Consequently, subjecting different carbons to the same chemical treatments will not necessarily lead to similar results.

\section{Effects of preoxidation on catalytic activity}

The activities of the catalysts prepared on the parent and the preoxidized carbons, as well as that of an equivalently loaded $\gamma-\mathrm{A}_{2} \mathrm{O}_{3}$ catalyst, are presented in Figure 3 . The asphal tene conversions and $C_{1}-C_{4}$ yields obtained in a blank run using the unloaded and untreated support were $8.5 \%$ and $7.5 \%$, respectively. Also shown in the figure are the percentage increases in catalyst weight due to the deposition of carbonaceous (THF insoluble) reaction products. The nature of these 


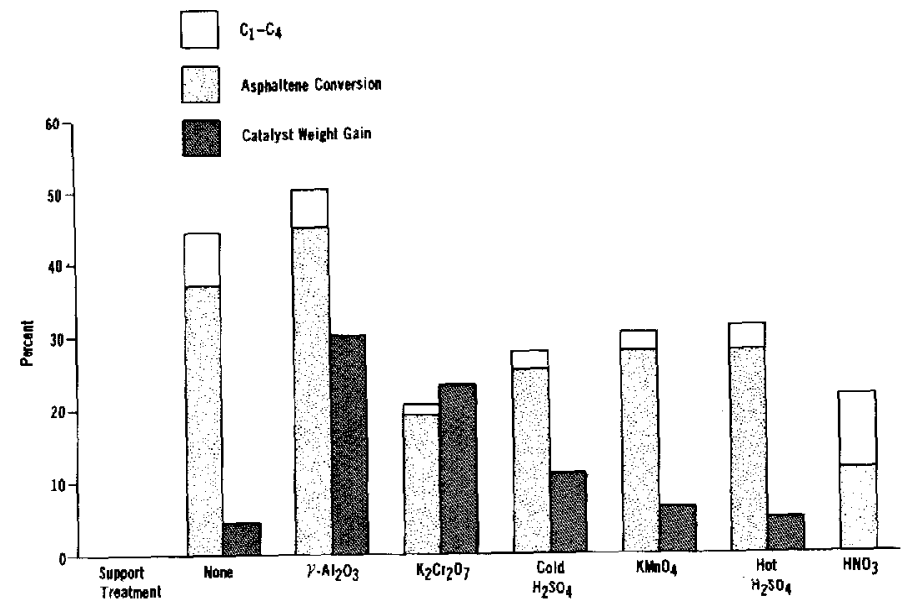

FIGURE 3 ReTative activities of Mo/C catalysts prepared on pre-oxidized supports.

deposits has not yet been determined and is the subject of continuing studies.

The reported activities, having been determined under similar reaction conditions, are related to the unit masses of catalyst and of molybdenum. Of course, there are other ways of expressing the catalyst activities, the activity per unit area of the support surface being the most obvious. In this case, there would be a change in the ranking order. However, it is probable that there are significant differences in the dispersion of the active molybdenum species on the variously treated supports. Since the dispersion cannot be quantified, it is considered that a more realistic practical means of comparing activities is in relation to the mass of catalyst and this is the basis used in the following discussion.

The principal feature of the data shown in Figure 3 is that preoxidation of the carbon supports reduced the activities of all of the catalysts for asphalteneoil conversion. For those catalysts prepared on the acid treated supports, the low catalyst activities can be explained by the greatly reduced surface areas of the carbons (Table 1).

For the carbons preoxidized with $\mathrm{K}_{2} \mathrm{Cr}_{2} \mathrm{O}_{7}$ and $\mathrm{KMnO}_{4}$, the reductions in catalyst activity cannot be attributed to changes in surface area alone. One possible explanation is that the effects of oxidation were to remove or modify the surface groups present on the untreated Ambersorb, such as aromatic ring substituents and conjugated double bonds, which are preferred sites for interaction with Mo species. The reduced interaction would correspond to the observations made from the FTIR spectra of the carbons and catalysts. In turn, it would be anticipated that a weaker interaction between the surface and metal species would result in a lower dispersion, consistent with the decrease in activity.

However, the possible influence of the residual potassium on catalyst activity cannot be ignored. Bridgewater et a]. [13] found that small quantities of potassium 
acted as a poison to carbon-supported molybdenum catalysts for synthes is gas reactions. The authors noted that this finding was in contrast to other published observations.

In their study of thiophene hydrodesulfurization (HDS) over $\mathrm{MOS}_{2} / \mathrm{C}$ catalysts, Vissers et al. [7] found that nitric acid pretreatment increased the activities of some carbon supported molybdenum catalysts and reduced them in other cases. They suggested that when the activity was enhanced, the high concentration of oxygen functional groups had a promotional effect on metal dispersion; for the cases where low activity was observed, the molybdate ions were weakly bonded to the carbon surface due to low concentrations of oxygen functional groups. This, they suggested, favored the mobility of the Mo species and resulted in sintering under reaction conditions. The sintering caused poor dispersion and hence low HDS activity.

However, these workers did not present information on the dispersion of the surface metal species. Neither was it apparent that the support surface areas had been determined after reaction with $\mathrm{HNO}_{3}$, the conditions for which were at least as severe as those employed in the research reported here. It is therefore possible that changes in support textural properties may account, at least in part, for the apparently unpredictable effects of preoxidation upon catalyst activity. During carbon oxidation, there is usually an increase in surface area due to the generation of new porosity. This is balanced by the loss of carbon and the enlargement of existing pores. Eventually the surface area passes through a maximum and begins to decrease [12]. Depending upon the susceptibility of the different carbons to $\mathrm{HNO}_{3}$ oxidation it is quite possible that, in some cases, the final surface area was greater than that of the starting material and, in others, it was lower.

From the foregoing, the thesis that the introduction of oxygen functionality can promote catalytic activity, possibly through providing preferred sites for the attachment of metal species and, thus, enhancing dispersion, cannot be unequivocally established since there are other possible explanations for the changes in activity caused by support oxidation.

The results obtained with catalysts prepared on the carbon black composite (CBC) support are presented in Table 3 and appear to show more directly that oxygen surface functionality can be instrumental in increasing catalytic activity. The catalyst prepared on the parent $C B C$ support possessed virtually no activity for asphaltene conversion. Following reaction in boiling conc. $\mathrm{HNO}_{3}$ for $2 \mathrm{~h}$, the oxygen content was increased from $<0.3$ to $2.3 \%$ with an increase in surface area of around $30 \%$. The support pretreatment also effected a substantial increase in the activity of the prepared catalyst and the full extent of this increase cannot be simply attributed to the increase in surface area.

From the results shown in Table 1 , it is 7 ikely that the acid treatment also introduced nitrogen functionality. The FTIR spectrum of the similarly treated Ambersorb carbon indicated that much of this nitrogen was in the form of nitrogen- 


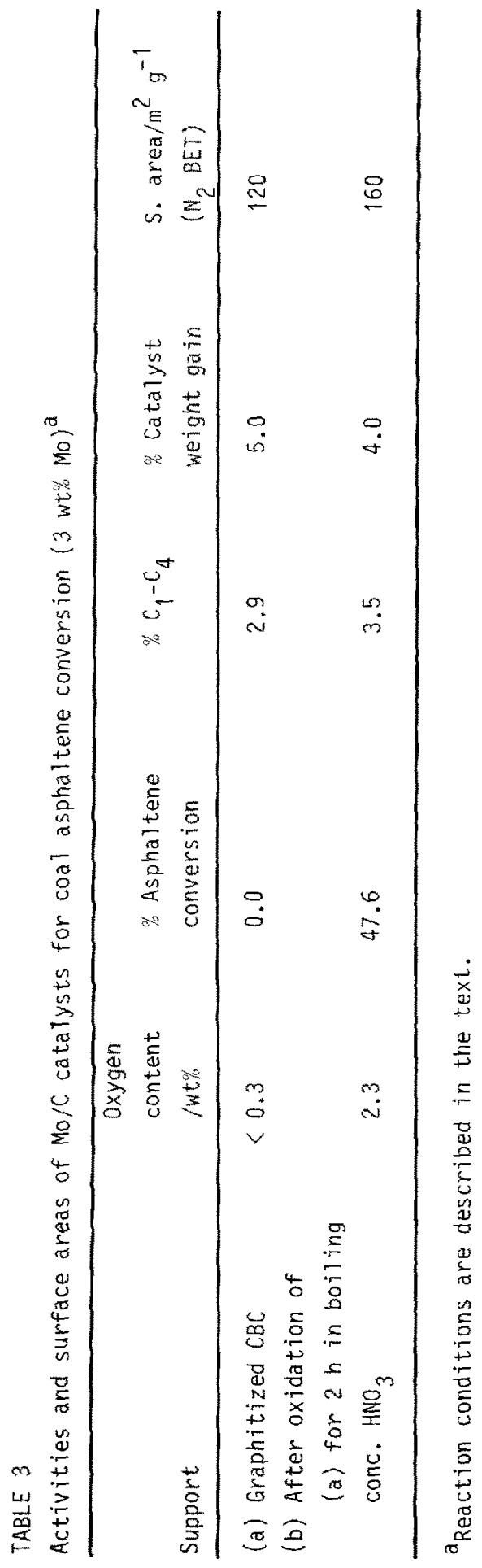


oxygen complexes. At this point, it cannot be stated whether the increase in catalyst activity is related to the presence of these particular functionalities.

Analysis of the carbons and catalysts by FTIR did not provide any further information. All of the spectra were featureless, which is believed to be due to the low concentration of functional groups, the graphitic nature of the carbon and the high absorption of the infrared beam.

In synopsis, there is some qualitative evidence to advocate that oxygen functionality might advantageously alter catalyst activity. The results presented and discussed also indicate that carbon surface oxidation can, in some cases, reduce catalyst activity. It is suggested that the effect of surface treatment is dependent upon the structure of the parent carbon and that this, essentially, is the controlling factor. For example, it appears that certain surface sites, extant on the parent Ambersorb carbon, provided a more favorable interaction with the deposited metal species than those resulting from oxidative treatment.

\section{Effects of ammonia pretreatment on catalytic activity}

In Figure 4, the activities of catalysts prepared on the ammonia pretreated carbon supports are compared with those of the untreated support and of the $\gamma_{-} \mathrm{Al}_{2} \mathrm{O}_{3}$ supported catalyst. The figure also shows the extent of coke formation on these cata7ysts.

In contrast to the effects of oxidative pretreatment, nitriding by reaction with $\mathrm{NH}_{3}$ promoted catalytic activity, which increased with the nitrogen content of the supports. The surface areas $\left(\mathrm{N}_{2}, 3 E T\right.$ at $\left.77 \mathrm{~K}\right)$ of the original and the nitrided $\left(\mathrm{NH}_{3}, 600^{\circ} \mathrm{C}\right)$ carbons are $399^{2}$ and $365 \mathrm{~m}^{2} \mathrm{~g}^{-1}$, respectively. Hence the high activity of the cataTyst prepared on the nitrided carbon cannot be explained by the change in surface area. It is considered that the increased activity is due to the interaction between the incorporated nitrogen and the metal species. The FTIR spectrum for the catalyst prepared on the support treated in $\mathrm{NH}_{3}$ at $600^{\circ} \mathrm{C}$ indicated that there may be some chemical interaction between the support and the metal species. This postulate is supported by the changes in the FTIR spectrum of poly-4-vinylpyridine upon metal loading (Figure 2).

The increase in activity of carbon-supported catalysts due to prenitriding was accompanied by only small increases in coke formation. In both instances, the extent of coke formation was much lower than obtained on the $\gamma-\mathrm{Al}_{2} \mathrm{O}_{3}$ supported catalyst. Presumably this can be related to the much lower concentration of acid sites which would be present on carbon compared to alumina surfaces.

\section{SUMMARY}

In this work, the activities of catalysts, prepared on preoxidized and prenitrided Ambersorb XE-340 carbon and on a preoxidized carbon black composite (CBC) support have been investigated for asphaltene conversion.

Preoxidation of the Ambersorb supports reduced catalyst activity. In some cases 


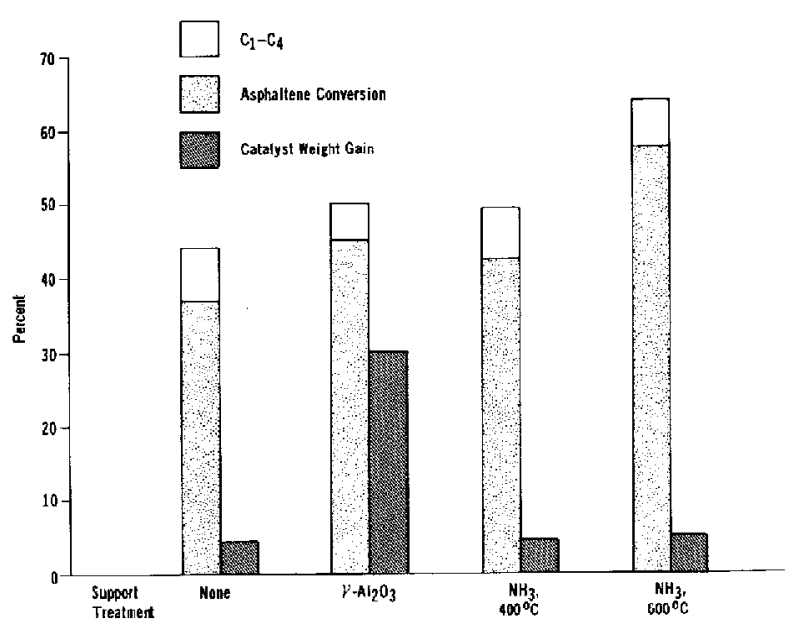

FIGURE 4 Relative activities of Mo/C catalysts prepared on pre-nitrided supports.

the decrease in activity was clearly due to loss of support surface area. Preoxidation of the $C B C$ support enhanced activity. While it has not bcen unambiguously demonstrated, it is considered that the effect of oxygen surface functionality on catalyst activity is dependent upon the structure of the carbon itself. In some cases, oxidation may provide preferred sites for the interaction of metal species, thus promoting dispersion. For other carbons, oxidative treatment may modify or destroy existing sites would could otherwise have provided a more favorable interaction.

In contrast to the effects of preoxidation, prenitriding was found to have a distinct effect in enhancing catalyst activity. At the same time, there was no commensurate increase in coking propensity. It is hypothesized that the increased activity may be related to the presence of nitrogen-containing surface groups which provide preferential sites for the adsorption of Mo species.

The evidence from this and other studies indicates that the properties of carbon-supported catalysts can be significantly improved by the introduction of surface functional groups. However, the type and concentration of such groups will be controlled by the chemical structure of the carbon. The almost infinite variation which is possible in the structural composition of carbons may well provide the principal reason why different researchers working with their own selected carbons have produced conflicting results.

The importance of using carbons which have been well-characterized in terms of their physical and chemical structure does not appear to have been generally recognized in this field of research. Nonetheless, such information is essential to deriving any fundamental understanding of the chemistry of the catalytic processes. In view of the technical difficulties in achieving this objective, there 
is cause to consider the advantages which could be derived by different research groups adopting "standard" carbon supports.

It is also important to note that, in these studies, only one precursor compound was used and all of the foregoing discussion is concerned with the interaction of various carbon surfaces with this compound. Obviousiy, the affinity between a particular carbon surface and the precursor will depend upon the compatibility of the two chemical structures and it is quite possible that the activities of the oxidized Ambersorb samples could be improved by employing a different precursor. Some of our recent results, yet to be published, illustrate that the HDS activity of certain carbon-supported molybdenum catalysts can be greatly increased by loading the carbon with an organometallic molybdenum compound.

\section{ACKNOWL FDGEMENTS}

The authors wish to acknowledge the support of the U.S. Department of Energy (Contract DE-AC22083PC60050), the National Science Foundation (Grant No. INT8319488) and the North Atlantic Treaty Organization (Grant No. 615/83).

\section{REFERENCES}

1 V.H.J. de Beer, F.J. Derbyshire, C.K. Groot, R. Prins, A. W. Scaroni and J.M. Solar, Fuel, 63 (1984) 1095.

2 P. Fhrburger, D.P. Mahajan and P.L. WaTker, Jr., J. Cata1., 76 (1982) 241.

3 W.P. Hoffman, F.J. Vastola and P.L. Walker, Jr., Carbon, 23 (1985) 151.

4 H.P. Boehm, G. Mair, T. Stoehr, A.R. de Rincon and B. Tereczki, Fuel, 63 (1984) 1061.

5 T.A. Ryan and M.H. Stacey, Fuel, 63 (1984) 1101.

6 B. Nicolai, Ph.D. Dissertation, University of Essen, West Germany, 1982.

7 J.P.R. Vissers, T.J. Lensing, F.P.M. Mercx, V.H.J. de Beer and R. Prins, Third Int. Seminar on Hydrogen as an Energy Carrier, Lyon, France, May 1983.

8 J.E. Metcalfe, III, M. Kawahata and P.L. Walker, Jr, Fuel, 42 (1963) 233.

9 O.P. Mahajan and P.L. Walker, Jr., "Porosity of Coals and Coal Products", in Analytical Methods for Coal and Coal Products, Vol.I, Academic Press, 1978 (C. Karr, Jr., Ed.).

10 J.L. Schmitt, P.L. Walker, Jr., and G.A. Castellion, U.S. Patent 3,978,000, August 1976.

11 A.W. Naumann, A.S. Behan and E.M. Thorsteinson, Proc. Fourth Int1. Conf. on the Chemistry and Uses of Molybdenum, Golden, Co, 1982, pp.313-318.

12 M. Kawahata and P.L. Walker, Jr., Proc. Fifth Carbon Conf., Pergamon Press, NY, Vol.2, 1963, pp.251-263.

13 A.J. Bridgewater, R. Burch and P.C.H. Mitche1T, J. Catal., 78 (1982) 116. 